\title{
ADMINISTRADORES BRASILEIROS E INVESTIMENTOS ESTRANGEIROS
}

YOLANDA FERREIRA BALCÃO E LAERTE LEITE CORDEIRO

Que pensa o nosso dirigente empresarial a respeito do investimento privado alienígena que converge para o Brasil ?

$\mathrm{O}$ investimento privado estrangeiro ocasiona um impacto na comunidade sócio-econômico-política para a qual se dirige e onde, finalmente, se localiza. Esse impacto é sentido pelos cidadãos, pelos governos e, principalmente, em nosso entender, pela comunidade de emprêsas e negócios. $O$ administrador da emprêsa privada o sente de forma especial, na qualidade de participante ativo do processo dinâmico da vida empresarial, de vez que seus objetivos, suas diretrizes, suas decisões e seu próprio comportamento como administrador são afetados pelas várias formas em que se traduz aquêle impacto.

Nos últimos anos, a comunidade brasileira acolheu, em escala jamais observada, um afluxo de investimento privado alienígena que para cá se transportou em busca do campo fértil que uma nação em processo de desenvolvimento econômico oferece para sua aplicação (1).

YOLANDA FERREIRA BALCÃo - Professôra-Adjunta da Escola de Administração de Emprêsas de São Paulo, Departamento de Administração Geral e Relações Industriais.

LAERTE LEITE CORDEIRo - Professor-Adjunto da Escola de Administração de Emprêsas de São Paulo, Departamento de Administração Geral e Relações Industriais.

(1) Las Inversiones Privadas Estranjeras en la Zona Latinoamericana de Libre Comercio, CEPAL, dezembro de 1960, pg. 2. 
Do ponto de vista governamental, o impacto trazido pelo investimento estrangeiro parece ser altamente positivo, sendo acolhido como valiosa contribuição e desempenhando uma importante função perante nosso processo de desenvolvimento econômico. A opinião pública parece, em geral, dividir-se entre duas posições fundamentais: de um lado, um sentimento nacionalista arraigado; de outro, uma franca aprovação pela entrada, no país, de investimento do exterior. Cabe, de imediato, a indagação : e que pensa o nosso administrador de emprêsas? Esta é a pergunta que nos propomos responder neste artigo, relato que é das informações colhidas através de um inquérito de opinião que realizamos junto a administradores brasileiros.

\section{Pressupostos e Metodologia}

Tomamos como pressuposto do inquérito que o impacto do investimento estrangeiro, no Brasil, em relação à imagem que dêle faz nosso administrador de emprêsas, se traduz, principalmente, em quatro áreas de investigação:

1. - a relação dêsse investimento com o desenvolvimento econômico do Brasil;

2. - os lucros das firmas estrangeiras em nosso país;

3. - as características dos administradores estrangeiros aqui radicados; $\mathrm{e}$

4. - as diretrizes e práticas administrativas das firmas estrangeiras no Brasil.

Em virtude do caráter preliminar de nossas hipóteses, decidimos inquirir, por meio de questionário impresso e enviado pelo correio, 150 administradores brasileiros, de diversos Estados da federação, ex-alunos do "Curso Intensivo para Administradores" da Escola de Administração de Emprêsas de São Paulo, selecionados ao acaso dentre aproximadamente 700 ex-alunos daquele curso.

Este grupo de administradores tem algumas características próprias que resultam: 
1) - dos requisitos para admissão ao curso (idade mínima de 25 anos; experiência mínima de 5 anos de trabalho, dos quais ao menos 3 em cargo administrativo; instrução mínima ginasial ou equivalente); e

2) - do treinamento específico que o curso lhes proporciona.

No mais, podemos crer que são administradores típicos, produto de nossa cultura e meio, expostos, como todos os executivos brasileiros, à influência do capital e administração alienigenas em nossa terra.

Dos questionários enviados recebemos 61, preenchidos, cujos resultados nos permitem concluir por algumas tendências bastante pronunciadas de atitudes e opiniões em relação aos tópicos incluídos no estudo.

Cabe, ainda, observar que citamos, no questionário enviado, apenas duas origens de investimentos, a americana e a alemã, deixando sempre ao livre critério dos respondentes as menções aos de outras nacionalidades.

Relataremos, a seguir, os resultados obtidos no inquérito, dividindo-os nas quatro áreas citadas de investigação, dentro das quais mencionaremos, pergunta por pergunta, número e natureza das respostas.

\section{Investimento Estrangeiro e Desenvolvimento Econômico}

Pergunta: É o investimento privado estrangeiro desejável para o desenvolvimento econômico do Brasil?

Conforme podemos observar através de um exame do Quadro I, o investimento privado estrangeiro é considerado desejável por todos os que nos responderam. Porém, ao passo que cêrca de metade dos mesmos julga que êsse investimento é desejável sem quaisquer restrições, os restantes consideram necessário que o mesmo seja acompanhado de certas restrições, dentre as quais, em ordem de importância, estão as seguintes:

a) - deve haver contrôle, limite ou regulamentação das remessas de lucros e dividendos ao exterior; 
b) - é necessário que haja reinvestimento total ou de grande parcela dos lucros no Brasil; e

c) - é necessário que o investimento não tenha a forma de "dumping", não seja excessivamente vultoso e não venha a destruir as emprêsas já existentes no país em virtude de seu poderio econômico (2).

\section{QUADRO I}

Respostas à pergunta: "É o investimento privado estrangeiro desejável para o desenvolvimento econômico do Brasil?"

\begin{tabular}{|c|c|c|c|}
\hline $\begin{array}{c}\text { ORIGEM } \\
\text { DO CAPITAL }\end{array}$ & $\operatorname{sim}$ & $\begin{array}{c}\text { SIM, COM } \\
\text { RESTRIÇŌES }\end{array}$ & NÃo \\
\hline $\begin{array}{l}\text { ESTRANGEIRO } \\
\text { EM GERAL }\end{array}$ & 31 & 30 & 0 \\
\hline DA ALEMANHA & 31 & 29 & 1 \\
\hline DOS ESTADOS UNIDOS & 31 & 29 & 1 \\
\hline DE OUTROS PAÍSES* & 38 & 22 & $\mathbf{I}$ \\
\hline
\end{tabular}

Pergunta: Se o investimento privado estrangeiro é desejável, é sua opinião que os interêsses do Brasil são melhor servidos pela formação de emprêsas com capital brasileiro e estrangeiro?

O Quadro II nos fornece as respostas a esta pergunta. Para a grande maioria dos respondentes, os interêsses do Brasil seriam melhor atendidos se o investimento privado estrangeiro que para cá converge se associasse ao capital nacional para a formação de emprêsas com capital misto. Embora

(2) Podemos afirmar, com um grau de $95 \%$ de fidedignidade, que mais de $40 \%$ dos administradores consultados são favoráveis ao investimento privado estrangeiro sem restrições e que mais de $96 \%$ são favoráveis a êsse investimento, com ou sem restrições.

$\mathrm{Na}$ hipótese de não haver diferenças fundamentais de atitude entre os respondentes e os administradores brasileiros em geral, poderíamos estender essa conclusão a todos os executivos brasileiros. 
se possa observar uma pequena diferença entre as respostas oferecidas para o tema geral e aquelas dadas ao investimento de origens específicas, ainda uma vez parece não haver fortes restrições ou preferências.

Este resultado parece corroborar as conclusões oferecidas num estudo feito pela CEPAL, em que se lê: "A atitude do setor comercial nacional, com respeito ao investimento privado estrangeiro, pode resumir-se como... de preferência pelas emprêsas mistas nacionais-estrangeiras, mais do que pelas puramente estrangeiras" (3).

\section{QUADRO II}

Respostas à pergunta: "Se o investimento privado é desejável, é opinião que os interêsses do Brasil são melhor servidos pela formação de emprêsas com capital brasileiro e estrangeiro?"

\begin{tabular}{|c|c|c|}
\hline CAPITAL & $\sin$ & NX̃o \\
\hline $\begin{array}{l}\text { BRASILEIRO E ESTRANGEIRO } \\
\text { EM GERAL }\end{array}$ & $\mathbf{s 5}$ & 6 \\
\hline BRASILEIRO E ALEMX̃o & 47 & 9 \\
\hline BRASILEIRO E AMERICANO & 47 & 9 \\
\hline $\begin{array}{l}\text { BRASILEIRO E DE } \\
\text { OUTROS PAÍSES* }\end{array}$ & 44 & 7 \\
\hline
\end{tabular}

Pergunta: É sua opinião que as firmas estrangeiras radicadas no Brasil vêm contribuindo para o desenvolvimento econômico do País?

Depois de afirmar ser o investimento privado estrangeiro desejável, o grupo inquirido nos oferece sua opinião a respeito da contribuição das firmas estrangeiras radicadas em nosso país. No parecer da quase totalidade dos administradores consultados, elas realmente vêm contribuindo para o nosso desenvolvimento econômico (Quadro III).

(3) Op. cit., pg. 21. 


\section{QUADRO III}

Respostas à pergunta : "E sua opinião que as firmas estrangeiras radicadas no Brasil vêm contribuindo para o desenvolvimento econômico do País?"

\begin{tabular}{|c|c|c|}
\hline FIRMAS & $\operatorname{sim}$ & NÃo \\
\hline $\begin{array}{l}\text { ESTRANGEIRAS, } \\
\text { EM GERAL }\end{array}$ & 60 & 1 \\
\hline ALEMÃs & 58 & 2 \\
\hline AMERICANAS & 59 & 1 \\
\hline DE OUTROS PAISES* & 56 & 0 \\
\hline
\end{tabular}

Pergunta : Se, em sua opinião, as firmas estrangeiras vêm contribuindo para $\theta$ nosso desenvolvimento econômico, de que países essa contribuição tem sido maior em :

- capital e equipamento

- capacidade técnịca

- capacidade administrativa

- capacidade mercadológica ?

A quase totalidade dos respondentes, como vimos na pergunta anterior (Quadro III), é de opinião que as firmas estrangeiras aqui radicadas têm contribuído para o nosso desenvolvimento econômico. Pelas respostas dadas à pergunta ora formulada (Quadro IV), pode-se concluir que, no entender da maioria dos administradores consultados, os quatro fatôres mencionados têm representado contribuições importantes das firmas estrangeiras.

\section{QUADRO IV}

Respostas à pergunta : "Se, em sua opinião, as firmas estrangeiras vêm contribuindo para o nosso desenvolvimento econômico, de que países essa contribuição tem sido maior em : 
capital e equipamento, capacidade técnica, capacidade administrativa e capacidade mercadológica ?"

\begin{tabular}{|c|c|c|c|c|}
\hline & & $\begin{array}{l}N \\
N \\
\text { on }\end{array}$ & $\begin{array}{l}\text { ol de responde } \\
\text { respostas of } \\
\text { r: } 60\end{array}$ & ivas a pergunto \\
\hline FIRMAS & $\begin{array}{c}\text { CAPITAL } \\
\text { E } \\
\text { EQUIPAMENTO }\end{array}$ & $\begin{array}{c}\text { CAPACIDADE } \\
\text { TÉCNICA }\end{array}$ & $\begin{array}{c}\text { CAPACID ADE } \\
\text { ADMINIS- } \\
\text { TRATIVA }\end{array}$ & $\begin{array}{l}\text { CAPACIDADE } \\
\text { MERCADO- } \\
\text { LÓGICA }\end{array}$ \\
\hline AMERICANAS & 54 & 52 & 52 & 49 \\
\hline ALEMAs & 50 & 50 & 40 & 37 \\
\hline FRANCESAS & 31 & 25 & 21 & 19 \\
\hline INGLESAS & 30 & 26 & 24 & 19 \\
\hline ITALIANAS & 25 & 23 & 13 & 13 \\
\hline JAPONESAS & 19 & 19 & 9 & 9 \\
\hline CANADENSES & 7 & 2 & 2 & 1 \\
\hline suíças & 6 & 5 & 4 & 1 \\
\hline
\end{tabular}

Pergunta: Na sua opinião, qual tem sido a influência da política do Govêrno Brasileiro (restrições à importação, instrução 113 etc.) no momento do investimento de capital estrangeiro direto, no Brasil, nos últimos anos?

Os administradores consultados entendem, em sua grande maioria (46), que a influência tem sido grande. Um número relativamente menor (13) a percebe como tendo sido entre pequena e nula.

\section{Lucros de Firmas Estrangeiras}

Pergunta : E sua opinião que os lucros de firmas estrangeiras são maiores, equivalentes, ou menores dos que os de firmas brasileiras na mesma indústria?

Conforme se pode observar através do Quadro V, a maioria dos respondentes acredita que as firmas alemãs e americanas tenham lucros maiores do que as brasileiras. Por outro lado, pequeno é o número de administradores que os julga menores.

\section{QUADRO V}

Respostas à pergunta : "E sua opinião que os lucros de firmas estrangeiras são maiores, equivalentes, ou menores do que os de firmas brasileiras na mesma indústria?" 
Quanto a firmas de outras origens, mencionaram os respondentes Inglaterra, Itália e França, atribuindo-lhes também, em sua maioria, lucros maiores do que os de firmas brasileiras.

\begin{tabular}{|c|c|c|c|}
\hline & \multicolumn{3}{|c|}{ No rofal de respondentes: 61} \\
\hline FIRMAS & $\begin{array}{l}\text { LUCROS } \\
\text { MAIORES QUE OS DE } \\
\text { FIRMAS BRASILEIRAS }\end{array}$ & \begin{tabular}{|c|} 
LUCROS \\
EQUIVALENTES AOS DE \\
FIRMAS BRASILEIR AS
\end{tabular} & $\begin{array}{l}\text { LUCROS } \\
\text { MENORES QUE OS DE } \\
\text { FIRMAS BRASILEIRAS }\end{array}$ \\
\hline ALEMÃs & 31 & 2 & 14 \\
\hline AMERICANAS & 32 & 2 & 13 \\
\hline
\end{tabular}

Pergunta: Se as firmas alemãs e americanas têm lucros maiores do que as brasileiras, isso se deve a :

- equipamento superior

- maiores recursos financeiros

- maior volume de operações

- administração mais eficiente?

O Quadro VI nos mostra que, na opinião de grande parte dos respondentes, os lucros maiores dessas firmas se devem principalmente ao maior montante de recursos financeiros e ao equipamento superior de que dispõem.

\section{QUADRO VI}

Respostas à pergunta : "Se as firmas alemãs e americanas têm lucros maiores do que as brasileiras, isso se deve a : equipamento superior, maiores recursos financeiros, maior volume de operações, administração mais eficiente ?"

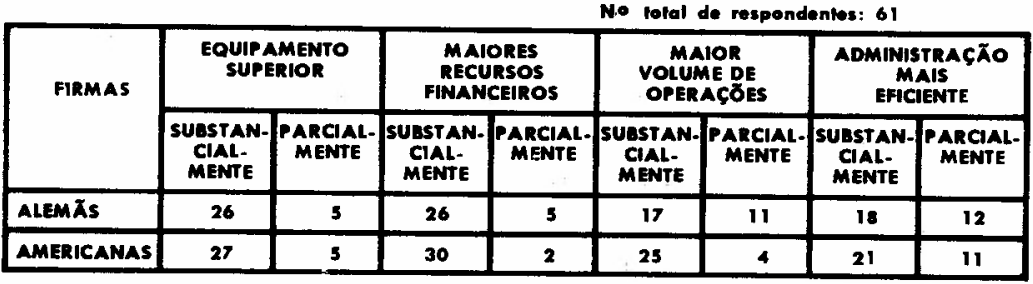

Pergunta : É sua opinião que deveriam ser colocados limites no montante de lucros de firmas estrangeiras a ser remetido para o exterior ? 
Se $\operatorname{sim}$, indique razões :

(a) para evitar o esgotamento de divisas;

(b) para forçar as firmas estrangeiras a reinvestir lucros no Brasil;

(c) para desencorajar lucros elevados;

(d) para reduzir a exploração do Brasil.

Se não, indique razões :

(a) porque limitaria a contribuição das firmas estrangeiras ao nosso desenvolvimento econômico;

(b) porque desencorajaria o afluxo, para o Brasil, de capital estrangeiro.

Dos 61 respondentes, 51 afirmaram que deveriam ser colocados limites nas remessas de lucros para o exterior. Um número relativamente menor (8) respondeu que não, tendo 2 deixado de emitir opinião a respeito.

Quanto às razões justificativas da limitação no montante de lucros a ser remetido para o exterior, as menções foram as seguintes :

47 - para forçar as firmas estrangeiras a reinvestir lucros no Brasil ;

27 - para evitar o esgotamento de divisas ;

6 - para desencorajar lucros elevados ;

6 - para reduzir a exploração do Brasil ;

Os administradores que responderam que não deveriam ser colocados limites nas remessas de lucros para o exterior fizeram as seguintes menções :

8 - porque desencorajaria $\circ$ afluxo, para $o$ Brasil, de capital estrangeiro.

7 - porque limitaria a contribuição das firmas estrangeiras ao nosso desenvolvimento econômico. 
3. Características de Administradores Estrangeiros

Pergunta: (a) É sua opinião que os administradores estrangeiros, no Brasil, têm as seguintes características positivas :

- capacidade de comunicar-se claramente em português

- capacidade de integrar-se socialmente no meio brasileiro

- capacidade de reconhecer qualidades nos brasileiros

- cultura geral - interêsse pelas artes?

(b) E ainda sua opinião que essas características aumentam significativamente a eficácia profissional de tais administradores?

Pergunta : (a) E sua opiniầo que os administradores estrangeiros, no Brasil, têm as seguintes características negativas :

- incapacidade de comunicar-se claramente em português

- recusa a aceitar os usos e costumes brasileiros

- complexo de superioridade

- materialismo excessivo, falta de interêsse pelas artes etc.?

(b) E ainda sua opinião que essas características limitam significativamente a eficácia profissional de tais administradores?

O interêsse, nestas perguntas, está na opinião que o administrador brasileiro tem a respeito de seu colega alienígena aqui radicado. Em se comparando os resultados contidos nos Quadros VII e VIII, podemos inferir que, para a maioria dos respondentes, os administradores alemães e americanos se 


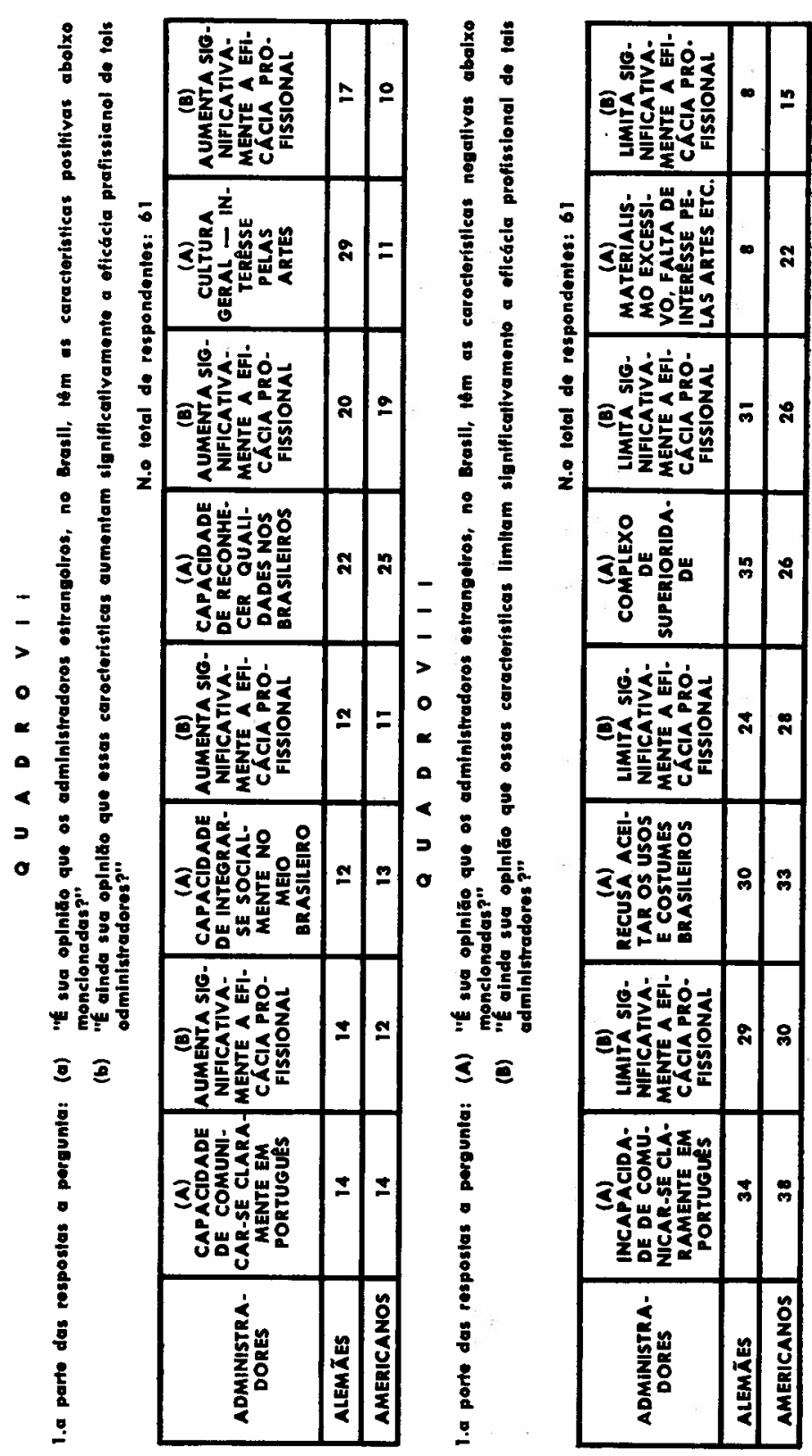




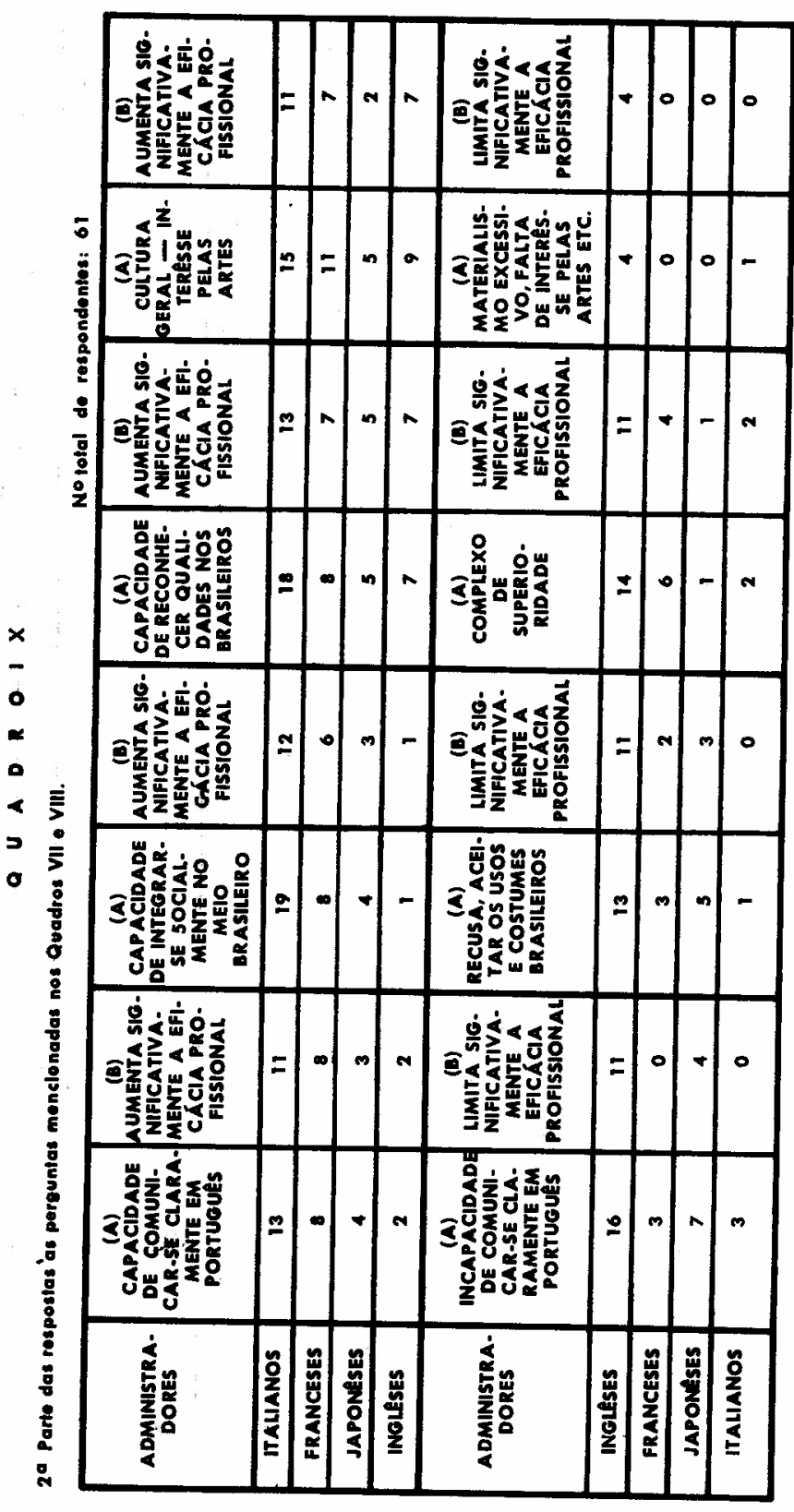


assemelham em têrmos de sua incapacidade de comunicar-se claramente em português, de sua recusa a aceitar nossos usos e costumes e de sua manifestação de complexo de superioridade. Nossos inquiridos distinguem marcadamente entre as duas nacionalidades apenas em relação à cultura geral, atribuindo essa qualidade positiva ao colega alemão, mas negando-a ao americano.

Como se pode observar no Quadro VIII, a maioria dos respondentes que atribuem a administradores alemães e americanos características negativas julga que elas vêm contribuindo para limitar significativamente a eficácia profissional dêsses administradores no desempenho de suas funções.

Por outro lado, embora minoritários, aquêles que vêem nos administradores alemães e americanos características positivas ressaltam que elas aumentam a eficácia profissional de tais administradores.

Quanto a administradores estrangeiros de outras nacionalidades, foram mencionados pelos respondentes os franceses, inglêses, italianos e japonêses. De interêsse é notar que os resultados apresentados no Quadro IX conferem aos administradores franceses e italianos uma imagem favorável, de vez que, na opinião da maioria dos que os mencionaram, os mesmos não têm nenhuma das características negativas incluídas na pergunta. Os administradores inglêses, por sua vez, acompanham de perto a linha de imagem referente aos alemães e, quanto aos japonêses, a opinião se divide entre características positivas e negativas.

\section{Diretrizes e Práticas de Firmas Estrangeiras}

Pergunta: (a) E sua opinião que as firmas estrangeiras, no Brasil, obedecem às seguintes diretrizes e práticas que criam impressão favorável em nosso país :

- utilização de brasileiros para cargos de importância

- reinversão de lucros 
- pagamento de salários equivalentes a brasileiros e estrangeiros

- adoção de diretrizes e práticas aplicáveis à realidade brasileira

- fabricação, no Brasil, de produtos de qualidade idêntica aos fabricados no país de origem

- concorrência a firmas brasileiras ?

(b) E ainda sua opinião que essas diretrizes e práticas aumentam significativamente a eficiência de tais firmas?

Pergunta: (a) É sua opinião que as firmas estrangeiras, no Brasil, obedecem às seguintes diretrizes e práticas que criam impressão desfavorável em nosso país :

- utilização de estrangeiros em cargos que podem ser desempenhados por brasileiros

- remessa de lucros ao exterior

- pagamento de salários desiguais a brasileiros e estrangeiros

- adoção de diretrizes e práticas que talvez não sejam aplicáveis à realidade brasileira

- fabricação, no Brasil, de produtos de qualidade inferior à dos fabricados no país de origem

- concorrência a firmas brasileiras?

(b) E ainda sua opinião que essas diretrizes e práticas limitam significativamente a eficiência de tais firmas?

Os Quadros X e XI nos levam a concluir que a fabricação, no Brasil, de produtos de qualidade idêntica à daqueles produzidos no país de origem das firmas é, segundo a maioria dos respondentes, prática favorável que é seguida pelas firmas alemãs e americanas radicadas no país. Por outro lado, a utilização de estrangeiros em cargos que podem ser desem- 

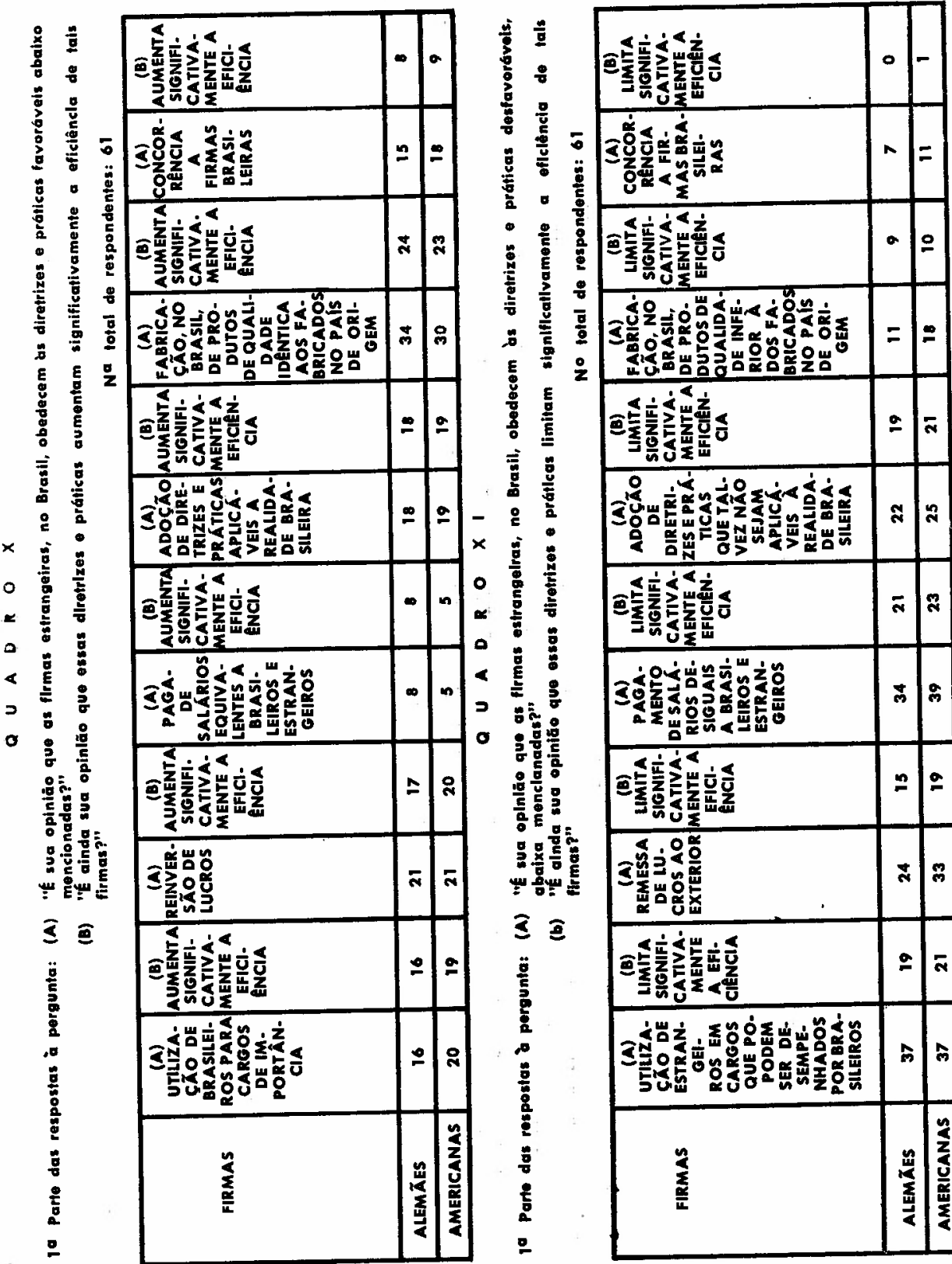


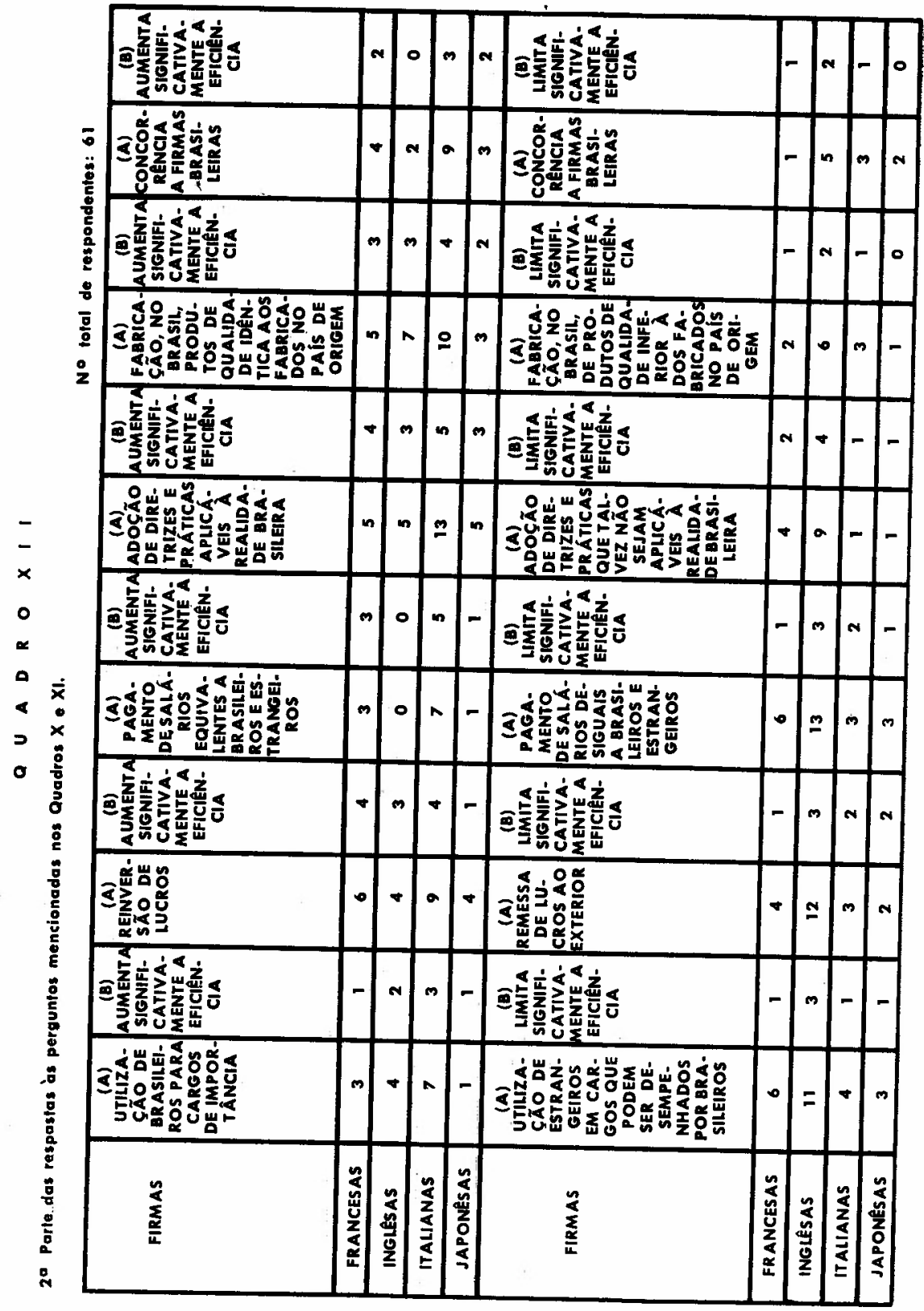


penhados por brasileiros e o pagamento de salários desiguais a brasileiros e estrangeiros representam, na opinião da maior parte dos que nos responderam, práticas desfavoráveis que são seguidas por essas firmas.

É interessante notar, entretanto, que nem todos os que lhes atribuem tais práticas acreditam que as mesmas limitem significativamente a eficiência das emprêsas americanas e alemãs em nosso país.

O fator "concorrência a firmas brasileiras" que, em nosso questionário, julgamos conveniente colocar como positivo $\mathrm{e}$ negativo, foi tido, pelos respondentes, como predominantemente favorável.

Quanto às firmas estrangeiras oriundas de outros países, foram mencionadas, ainda uma vez a critério espontâneo dos respondentes, as francesas, inglêsas, italianas e japonêsas. As firmas inglêsas obedecem, na opinião dos respondentes, a práticas desfavoráveis, com exceção da fabricação, no Brasil, de produtos de qualidade idêntica à dos produzidos na Inglaterra. Ao contrário, as firmas italianas obedecem, na opinião dos respondentes, a práticas e diretrizes que criam impressão favorável no Brasil. O Quadro XII dá os resultados das menções feitas às diretrizes e práticas dessas firmas estrangeiras.

Pergunta : Em sua opinião, os seguintes fatôres influenciam a atitude dos brasileiros em relação às firmas estrangeiras :

- qualidade dos produtos e serviços

- relações das firmas com seus empregados

- comportamento e desempenho dos administradores estrangeiros no Brasil

- esforços de relações públicas das firmas estrangeiras no Brasil

- relações do govêrno estrangeiro com o brasileiro

- comportamento dos cidadãos estrangeiros no Brasil ? 
O objetivo desta pergunta era aquilatar da opinião dos administradores de emprêsas brasileiros quanto aos fatôres que influenciam a opinião pública brasileira em relação às firmas estrangeiras. Assim, segundo o Quadro XIII, vemos que a qualidade dos produtos e serviços é o fator que, no parecer dos respondentes, mais substancialmente influencia essa opinião, em relação às firmas alemãs e americanas. $O$ comportamento dos cidadãos alemães e americanos no Brasil influencia, também, substancialmente, a opinião dos brasileiros em relação a essas firmas.

Interessante é observar, entretanto, que alguma discrepância ocorre nas respostas dadas a outros itens da pergunta, pois notamos que, ao passo que as relações das firmas americanas com seus empregados influenciam, no entender de grande parte dos que nos responderam, substancialmente, a opinião dos brasileiros em relação a essas firmas, as relações das firmas alemãs influenciam apenas regularmente a opinião dos brasileiros quanto às mesmas. Os esforços de relações públicas das firmas alemãs e americanas apresentam a mesma discrepância. Fator de ainda maior divergência, as relações do govêrno americano com o brasileiro têm influência substancial, na opinião da maioria dos respondentes, na atitude dos brasileiros em relação às firmas americanas; as relações do govêrno alemão têm influência pequena ou nula na opinião pública brasileira com relação às firmas alemãs.

A qualidade dos produtos e serviços das firmas francesas, inglêsas, italianas e japonêsas, mencionadas a critério espontâneo dos respondentes, é o fator mais relevante para a atitude dos brasileiros em relação a essas firmas. Em relação aos demais itens da pergunta, sobressaem-se apenas o comportamento dos cidadãos italianos (que tem influência substancial na opinião pública brasileira quanto às firmas italianas) e o comportamento e desempenho dos administradores franceses no Brasil (que influenciam regularmente a atitude brasileira em relação às firmas francesas) (Quadro XIV). 


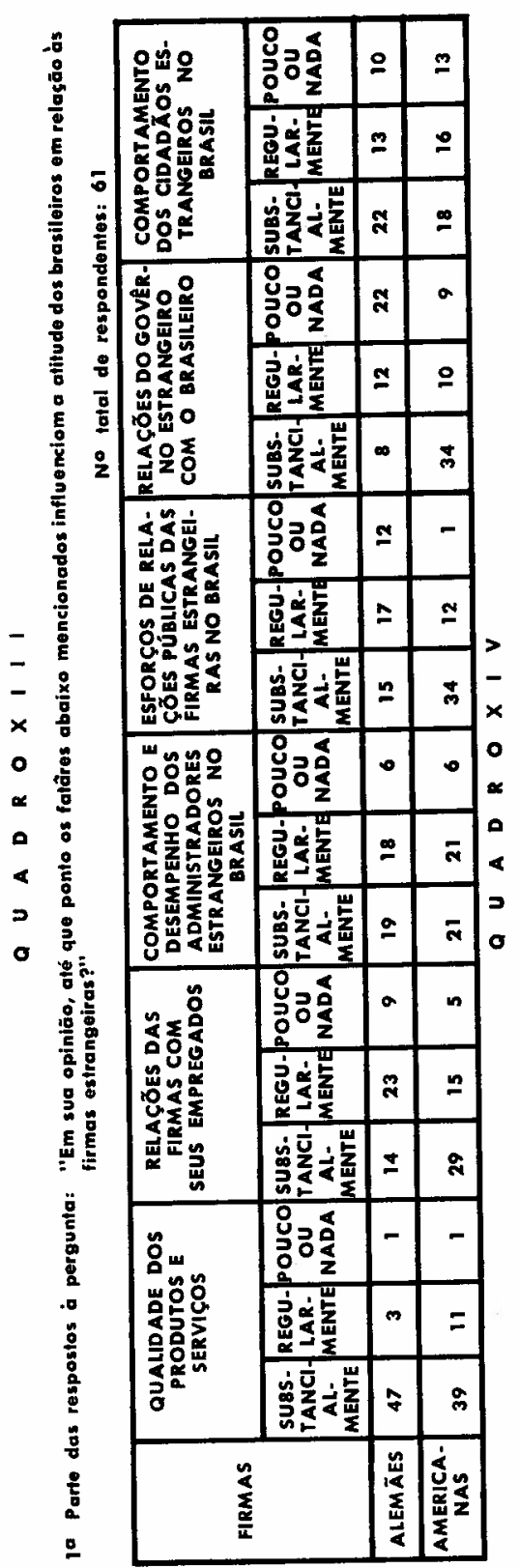

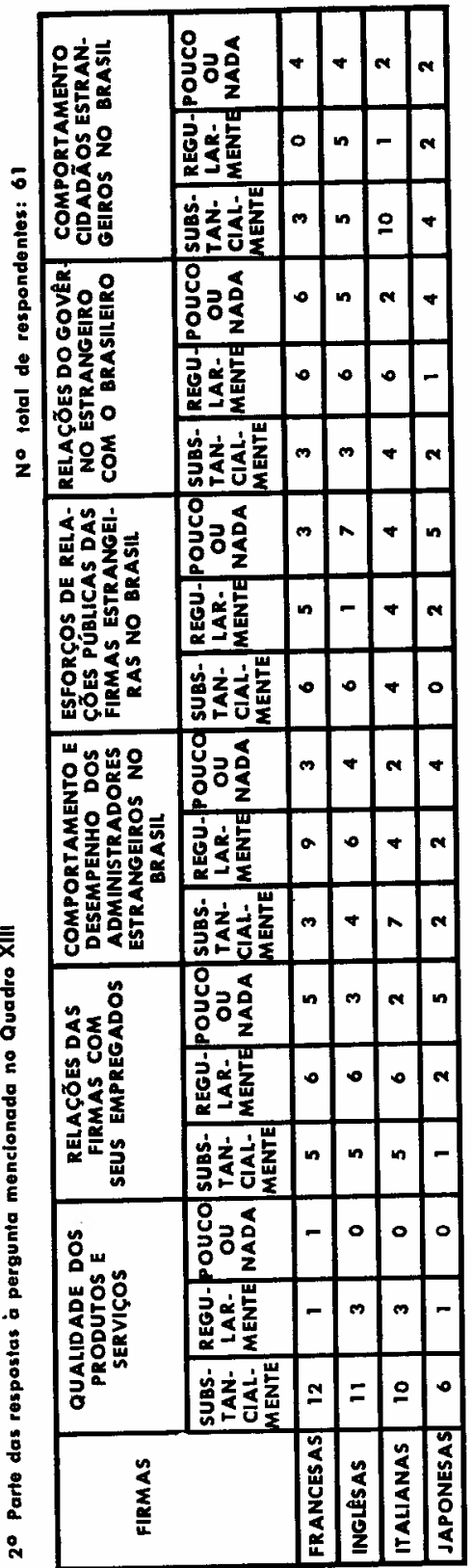




\section{Conclusões}

Certos resultados do inquérito apontam em direções bem definidas. Em sua primeira parte, por exemplo, permitem concluir que os administradores patrícios consultados julgam que o investimento privado estrangeiro, qualquer que seja sua origem, é desejável para o desenvolvimento econômico do país, mas, em grande parte, o aceitam com restrições destinadas a proteger a emprêsa nacional.

Nossos dirigentes recebem com entusiasmo a associação do capital nacional com capitais estrangeiros, forma em que, segundo a quase totalidade dos que nos responderam, são melhor servidos os interêsses do Brasil.

Assim, também, pràticamente todos os nossos respondentes afirmam que as firmas estrangeiras radicadas no Brasil vêm contribuindo para o nosso desenvolvimento econômico.

o limite na remessa de lucros para o exterior é outro tópico que nos dá uma posição definida : a grande maioria julga que o montante de lucros a ser remetido para o estrangeiro deva ser limitado, mas principalmente pelas razões de precaução econômica (para forçar as firmas a reinvestir lucros no Brasil e evitar o esgotamento de divisas).

Finalmente, quanto às características dos administradores estrangeiros e às diretrizes e práticas das firmas estrangeiras no Brasil, parece haver opinião principalmente favorável para firmas e administradores italianos, havendo, ao contrário, opinião predominantemente desfavorável em relação a firmas e administradores alemães e americanos.

Cremos não ser necessário que nos alonguemos na exposição de vantagens e benefícios trazidos pela pesquisa de opinião. Diremos apenas que no Brasil, em que as discussões, neste assunto, são estabelecidas em bases exclusivamente hipotéticas, sendo a opinião empresarial objeto de conjeturas ou afirmações apriorísticas, as informações da pesquisa junto a administradores podem constituir pontos de partida para estudos mais sistemáticos e aprofundados, já agora em bases menos hipotéticas e mais fundamentadas. 